\title{
BMJ Open Case study of the beneficiary group distribution of curative care expenditure based on SHA 2011 in Xinjiang autonomous region, China
}

\author{
Honghong Feng (D) , ${ }^{1}$ Kai Pan, ${ }^{2}$ Xiaoju Li, ${ }^{1}$ Liwen Zhang, ${ }^{1}$ Lu Mao, ${ }^{1}$ \\ Dongsheng Rui (i) ${ }^{1}$
}

To cite: Feng $\mathrm{H}$, Pan $\mathrm{K}$, Li X, et al. Case study of the beneficiary group distribution of curative care expenditure based on SHA 2011 in Xinjiang autonomous region, China. BMJ Open 2021;11:e043155. doi:10.1136/ bmjopen-2020-043155

- Prepublication history for this paper is available online. To view these files, please visit the journal online (http://dx.doi org/10.1136/bmjopen-2020043155).

$\mathrm{HF}$ and KP contributed equally.

Received 25 July 2020 Accepted 14 May 2021

Check for updates

(C) Author(s) (or their employer(s)) 2021. Re-use permitted under CC BY-NC. No commercial re-use. See rights and permissions. Published by BMJ.

${ }^{1}$ Department of Public Health, Shihezi University School of Medicine, Shihezi, China

${ }^{2}$ Xinjiang Uighur Autonomous Region Center for Disease Control and Prevention, Wulumuqi, China

Correspondence to Dr Dongsheng Rui; ruidongsheng@shzu.edu.cn

\section{ABSTRACT}

Background The System of Health Accounts 2011 (SHA 2011) assists in health policy analysis and health expenditure comparison at the international level. Based on SHA 2011, this study analysed the distribution of beneficiary groups of curative care expenditure (CCE) in Xinjiang, to present suggestions for developing health policies.

Methods A total of 160 health institutions were selected using the multistage stratified random sampling method. An analysis of the agewise CCE distribution, institutional flow, and disease distribution was then performed based on the SHA 2011 accounting framework.

Results In 2016, the CCE in Xinjiang was $¥ 50.05$ billion, accounting for $70.18 \%$ of current health expenditure and $6.66 \%$ of the gross domestic product. The per capita CCE was $¥ 2366$.56. The CCE was distributed differently across age groups, with the highest spending on people over the age of 65 years. The CCE was highest for diseases of the circulatory, respiratory and digestive systems. Most of the expenditure was incurred in hospitals and, to a lesser extent, in primary healthcare institutions. Family health expenditure, especially on children aged 14 years and below, accounted for a relatively high proportion of the CCE.

Conclusion SHA 2011 was used to capture data which was then analysed according to the newly added beneficiary dimension. The findings revealed that the use of medical resources is low, the scale of primary medical institutions needs to be significantly expanded and there is a need to optimise the CCE financing scheme. Therefore, the health policymaking department should optimise the relevant policies and improve the efficiency of health services.

\section{BACKGROUND}

A country's health system provides its citizens with basic medical services, including health promotion, disease prevention, treatment, rehabilitation and hospice care. ${ }^{12}$ Although a few developed regions provide the full range of health services, from prevention to hospice care, the medical services in most other regions focus on therapeutic services.
Strengths and limitations of this study

- This study conducts in-depth analyses of key populations, key diseases and major institutions that consume curative care expenditure (CCE), and provides a reference for improving the efficiency of health services.

- CCE is analysed from the newly added beneficiary dimension of System of Health Accounts 2011 (SHA 2011).

- This study only analysed the data for 1 year and could not judge the change in CCE in Xinjiang.

- Only the overall beneficiaries of CCE in Xinjiang were analysed, and the region was not subdivided into different cities; therefore, we cannot present efficient policy suggestions for different cities.

- The methodology of the study is based on the SHA 2011 accounting framework developed by the China National Health Development Research Center according to the health of people in China; so there are certain limitations, and the results are not applicable to all countries.

In recent years, China's health expenditure has been growing, and the proportion of total health expenditure in terms of gross domestic product (GDP) is on the rise. ${ }^{3}$ Studies have shown that the curative expenditure in China accounts for $75.59 \%$ of current health expenditure (CHE), which indicates that health expenditure is mostly on treatment and rehabilitation, and less on prevention. ${ }^{45}$ This finding contradicts the goal of disease prevention in the Healthy China 2030 Plan, which emphasises the prevention and treatment of diseases. ${ }^{6}$

The existing literature also suggests that, due to the selective emphasis on curative services, the financial support provided to preventive health systems is inadequate, leading to a series of problems. ${ }^{78}$ The Center for Disease Control and Prevention is a major public health institution in China that 
provides preventive services. A lack of financial support for such institutions would weaken public health systems across regions, leading to inefficient disease control and a subsequent increase in the prevalence of infectious diseases. If public health institutions do not have the requisite funds for disease prevention and control, there will be a greater risk in terms of the spread of sudden infectious diseases. Events that harm public health not only increase the economic burden on the society but also hurt the lives and safety of people. ${ }^{910}$

How can these problems be solved? First, it is necessary to understand the curative care expenditure (CCE) of the main beneficiaries, the key diseases that account for the highest proportion of expenditure and major institution flows. Second, we must adjust the financial expenditure, make efficient use of the health fund and improve the efficiency of both preventive as well as curative services. Early prevention of major diseases and interventions for high-risk populations could lower the possibility of poor health, thereby reducing CCE in the future. ${ }^{11}$

To analyse health expenditure trends, international organisations have collectively formulated the 'System of Health Accounts 2011' (SHA 2011). SHA 2011 was published in 2011 by the Organisation for Economic Cooperation and Development, WHO, World Bank and other international organisations. Its purpose is to guide countries to produce National Health Accounts to enhance international and domestic comparisons of health account data over time. ${ }^{12}$ Compared with SHA 1.0, SHA 2011 added the dimension of health service beneficiaries to meet the needs of evolving healthcare systems. ${ }^{13}$
This study is based on the beneficiary dimension of SHA 2011 and analyses the distribution of CCE in China's Xinjiang Autonomous Region in 2016. It describes the matrix relationship between different age groups and diseases, institutional flows and financing schemes. In addition, it presents the status of health resource consumption in different populations and determines the key populations and diseases. Health data for Xinjiang are used as an example to explore the distribution of beneficiaries in relation to CCE and provide data support to improve the formulation of health-related policies.

\section{METHODS}

In July 2016, the China National Health Development Research Center organised a national conference in Beijing on the method training of SHA 2011, all regions of the country were expected to fully implement the SHA 2011 accounting framework. Xinjiang officially launched this accounting framework in 2016.

The SHA 2011 framework classifies healthcare expenditures based on the functions, provision and financing of healthcare. This classification is organised around a triaxial system of healthcare expenditure, as presented in figure $1{ }^{14}$ The framework addresses the following basic questions and describes the financial flow within the healthcare sector.

1. What kind of medical and healthcare supplies and services are consumed?

2. Which health service providers deliver these supplies and services?

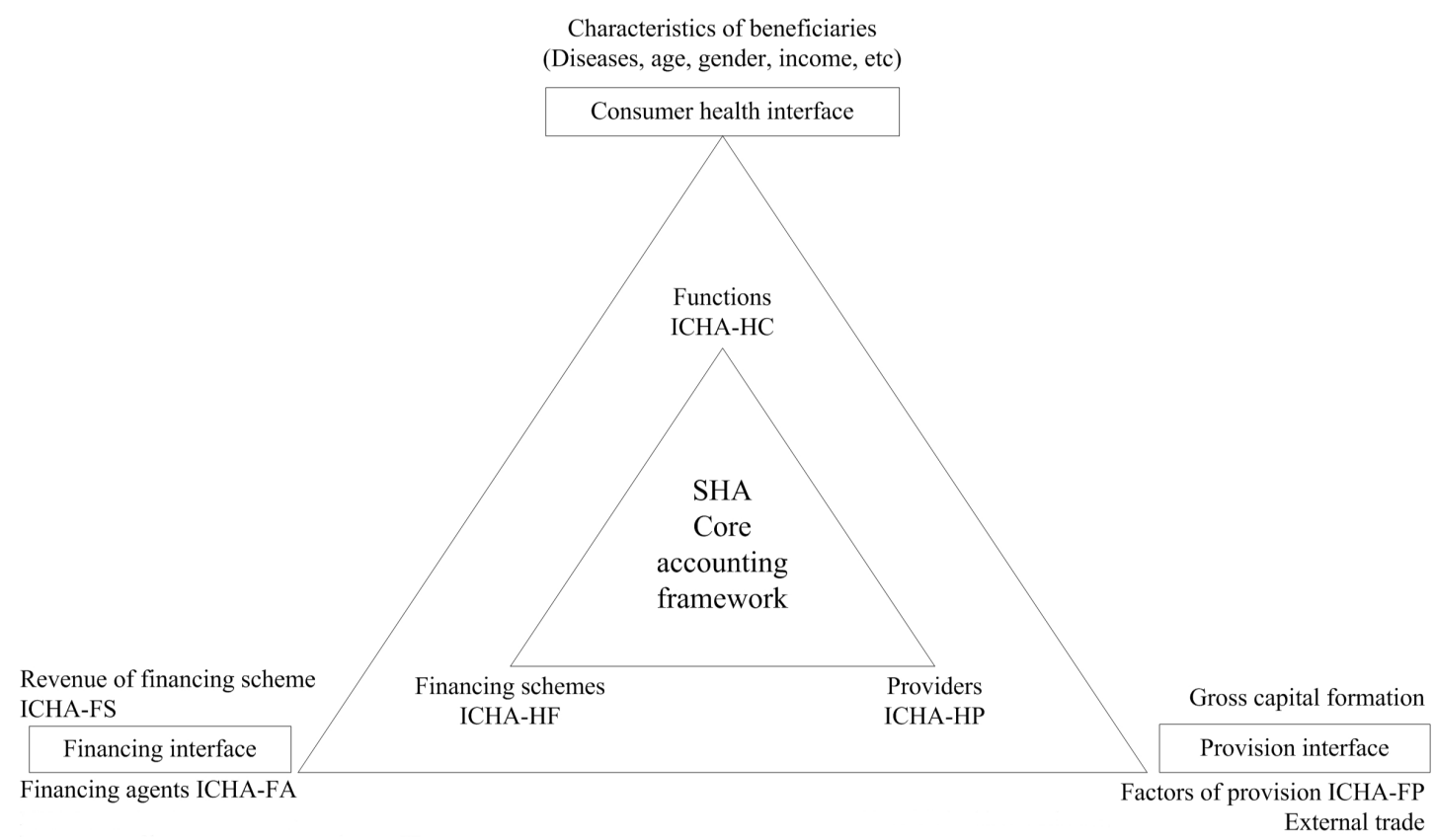

Figure 1 The core and extended accounting framework of SHA 2011. Source: IHAT for SHA 2011. FA, financing agents; FP, factors of healthcare provision; FS, revenues of healthcare financing schemes; HC, healthcare functions; HF, healthcare providers; HP, healthcare schemes; ICHA, International Classifications for Health Accounts; IHAT, International Health Accounts Team; SHA, System of Health Accounts. 
3. What financing scheme compensates for the use of these supplies and services?

\section{Data source}

This study adopted a top-down allocation method, which is based on the total amount of macro data. The allocation parameters were obtained using sample survey data. The data sources obtained in this manner are divided into two parts: macro-control data, which are obtained from different types of official statistics (Health Statistics Yearbook, Health Financial Annual Report and Government Health Input Testing System). The other is the data of allocation parameters, which are obtained from the survey. (The case database is from sample health institutions in Xinjiang. A total of 3 provincial, 11 municipals, 21 county and 125 township health institutions were selected from the five sample areas.)

\section{Data sample}

This study was based on the SHA 2011 and used the multistage stratified random sampling method. In the first stage, five sample areas were selected based on their economic development status and medical services level: Urumqi, Kashgar, Ili, Hami and Bayingolin Mongolian Autonomous Prefecture. Based on the comprehensive capabilities, working foundation and information construction of each medical institution, one city and two counties were chosen within each selected prefecture. Finally, five communities or townships were selected as samples from each of the selected cities and counties.

In total, 160 health institutions were selected. Data on outpatient and inpatient cases were collected from the sample survey institutions after cleaning the sample date. About 4.3 million cases met the requirements. These data were mainly used to calculate the allocation parameters of each dimension.

Sample institutions include hospitals (general hospital, traditional Chinese medical hospital and specialised hospital), maternal and child care centres, outpatient service institutions and primary health agencies. Survey indicators included age, gender, disease types, type of health insurance and out-of-pocket medical expenses.

\section{Statistical method}

In China, curative care services include treatment, rehabilitation and long-term care services. ${ }^{15}$ The three services are intertwined and difficult to separate.

Hospitals, public health institutions and basic medical institutions have the same method of calculating CCE. The following formula was used to calculate CCE:

$$
\mathrm{C}_{\mathrm{CCE}}=\sum_{\mathrm{K}=1}\left(\mathrm{C}_{\mathrm{KINC}}+\mathrm{C}_{\mathrm{KALL}}\right)
$$

where $\mathrm{C}_{\mathrm{KINC}}$ represents the curative income, $\mathrm{C}_{\mathrm{KALL}}$ represents the basic expenditure allowance and $\mathrm{K}$ represents the different medical institutions. Curative income refers to health facility through the provision of outpatient and inpatient services, obtained from the patient and the medical insurance fund compensation money.

The formula for calculating curative income is as follows:

$$
\begin{gathered}
\mathrm{C}_{\mathrm{INC}}=\mathrm{C}_{\mathrm{TINC}}\left(1-\frac{\alpha_{\mathrm{p}}}{\alpha}\right) \\
\mathrm{C}_{\mathrm{INC}}^{\prime}=\sum_{\mathrm{i}}^{\mathrm{n}}\left(\mathrm{C}_{\mathrm{INC}} \times \frac{\alpha_{\mathrm{i}}}{\alpha-\alpha_{\mathrm{p}}}\right)
\end{gathered}
$$

where $\mathrm{C}_{\text {TINC }}$ represents the actual total income, based on the Health Statistics Yearbook and Health Financial Annual Report, $\alpha$ represents the total curative income of the sample, $\alpha_{\mathrm{p}}$ represents the total curative income of the sample's preventive service, $\mathrm{C}_{\mathrm{INC}}^{\prime}$ represents the actual curative income and $\alpha_{i}$ represents the curative income of the sample patient. Curative income is calculated by excluding prevention income from medical income. The health facility sample included medical information on every patient in this facility. Sample patients are taken from facility samples.

The formula for calculating basic expenditure allowance is as follows:

$$
\mathrm{C}_{\mathrm{ALL}}^{\prime}=\sum_{\mathrm{i}}^{\mathrm{m}}\left[\left(\mathrm{C}_{\mathrm{TALL}}-\mathrm{C}_{\mathrm{PALL}}\right) \times \frac{\alpha_{\mathrm{i}}}{\alpha-\alpha_{\mathrm{p}}}\right]
$$

where $\mathrm{C}_{\mathrm{ALL}}^{\prime}$ represents the total actual basic expenditure allowance, $\mathrm{C}_{\text {TALL }}$ represents the basic expenditure allowance from the Health Statistics Yearbook and Health Financial Annual Report and $\alpha_{i}$ represents the curative income of the sample. $\mathrm{C}_{\mathrm{PALL}}$ represents the basic expenditure allowance of the preventive service. Basic expenditure allowance refers to the monetary subsidy provided by government departments to health facilities to ensure their normal operation and completion of daily tasks.

The analysis was performed using STATA V.12.0 and SPSS V.20.0 software.

\section{Patient and public involvement}

We were entrusted by the Autonomous Region Health Commission to undertake this research and collect data from sample facilities. No personal information related to the patient's name, identification number and other private information was used, so there is no privacy infringement problem and no patients were directly involved in the study.

\section{RESULTS}

\section{Basic information about the CCE of different age groups in Xinjiang in 2016}

In 2016, the CCE in Xinjiang was ¥50.05 billion, accounting for $70.18 \%$ of the CHE and $6.66 \%$ of the region's GDP. The per capita CCE was ¥2366.56. From the perspective of medical service function, the majority of CCE was incurred on inpatient expenditure, which was ¥32.969 billion, accounting for $65.88 \%$ of CCE. Outpatient expenditure was $¥ 17.075$ billion, accounting for $34.12 \%$ of CCE.

The results of CCE for different age groups showed that CCE changed with age, increasing for the group aged 0-14 years. For the group aged 15-54 years, CCE continued to increase with age, reaching the highest expenditure in the 
Table 1 Curative care expenditure in Xinjiang by age group in 2016

\begin{tabular}{|c|c|c|c|c|c|c|}
\hline Age (years) & Total/billion CNY & Ratio/\% & Outpatient/billion CNY & Ratio/\% & Inpatient/billion CNY & Ratio/\% \\
\hline $0 \sim$ & 2.46 & 4.92 & 0.75 & 4.42 & 1.71 & 5.18 \\
\hline $5 \sim$ & 1.32 & 2.64 & 0.78 & 4.55 & 0.55 & 1.66 \\
\hline $15 \sim$ & 0.97 & 1.97 & 0.47 & 2.73 & 0.52 & 1.58 \\
\hline $20 \sim$ & 1.52 & 3.04 & 0.68 & 4.00 & 0.84 & 2.53 \\
\hline $35 \sim$ & 2.75 & 5.50 & 1.10 & 6.45 & 1.65 & 5.00 \\
\hline $40 \sim$ & 3.98 & 7.95 & 1.46 & 8.56 & 2.52 & 7.63 \\
\hline $45 \sim$ & 4.86 & 9.71 & 1.68 & 9.81 & 3.19 & 9.66 \\
\hline $50 \sim$ & 5.09 & 10.18 & 1.71 & 10.02 & 3.38 & 10.26 \\
\hline $75 \sim$ & 2.94 & 5.88 & 0.73 & 4.29 & 2.21 & 6.70 \\
\hline $80 \sim$ & 1.54 & 3.07 & 0.41 & 2.40 & 1.13 & 3.42 \\
\hline $85 \sim$ & 0.66 & 1.33 & 0.18 & 1.03 & 0.49 & 1.48 \\
\hline $90 \sim$ & 0.17 & 0.34 & 0.05 & 0.28 & 0.12 & 0.37 \\
\hline$\geq 95$ & 0.03 & 0.07 & 0.01 & 0.04 & 0.03 & 0.08 \\
\hline Total & 50.05 & 100.00 & 17.08 & 100.00 & 32.97 & 100.00 \\
\hline
\end{tabular}

CNY, Chinese yuan.

50-54 age group. After 55 years of age, the CCE declined. Different age groups consume different degrees of health resources and expenditure, therefore, CCE also changes with age (table 1$)$.

Comparing the proportion of each age group in the total resident population with that of its $\mathrm{CCE}$, the proportion of CCE for those under 64 years was lower than the share of this proportion in the total population, especially for those under 14 years. The proportion of CCE for those over 65 years was significantly higher than the share of this proportion in the overall population, indicating that the elderly population consumed more medical resources (figure 2).

\section{Disease distribution of CCE in different age groups}

According to the classification criteria of the main chapter of the International Classification of Diseases 10th Revision,

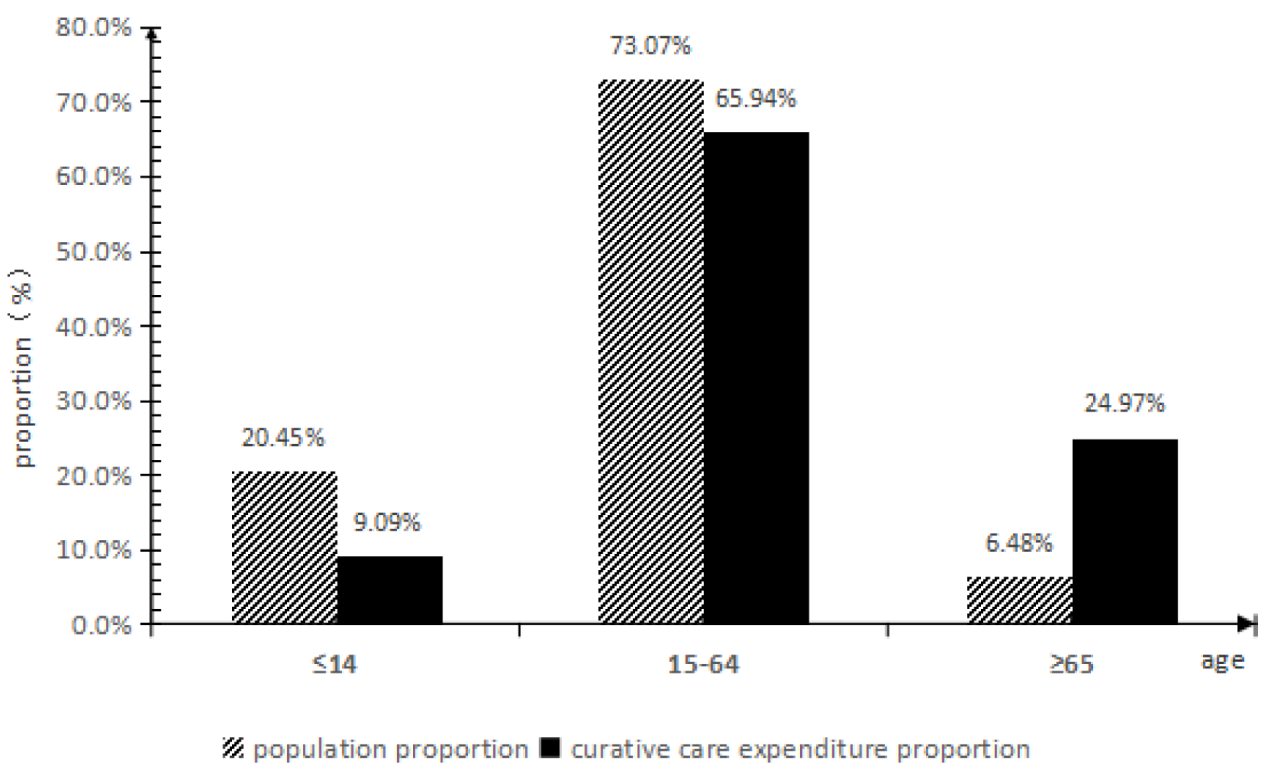

Figure 2 The proportion of the population and curative care expenditure accounting for age groups. 
Table 2 Curative care expenditure by disease and age groups (\% )

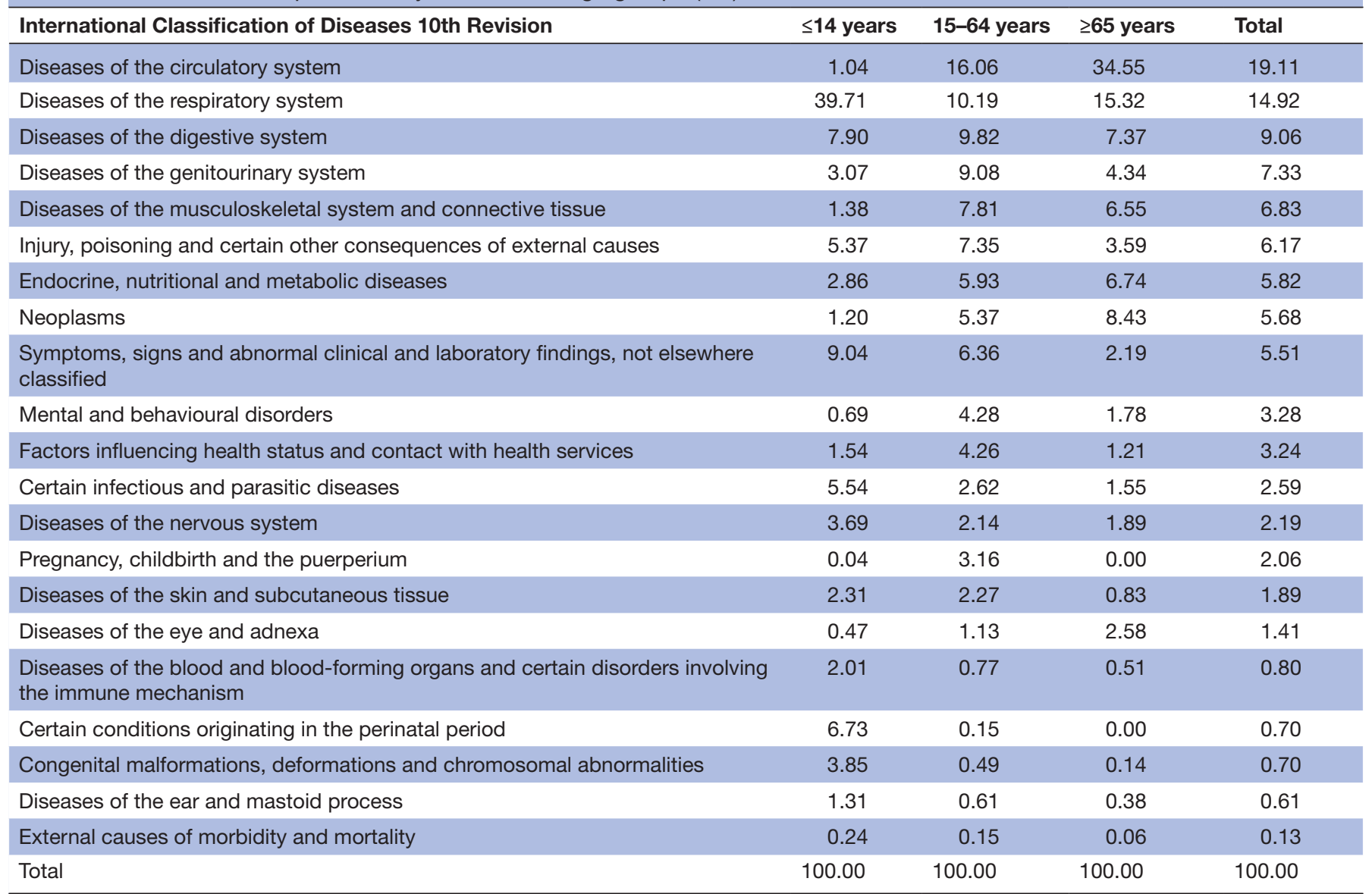

the top five CCEs in Xinjiang were for diseases of the circulatory system, respiratory system, digestive system, genitourinary system, musculoskeletal system and connective tissue, which totalled $¥ 28.646$ billion and accounted for $57.24 \%$ of the total curative health expenditure. The composition of diseases that require medical resources is different across age groups. Among those under 14 years, the highest $\mathrm{CCE}$ was for respiratory system diseases, at $39.71 \%$, followed by symptoms, signs and clinical and laboratory abnormalities, and digestive diseases. For the 15-64 years age group, the highest CCE was for circulatory diseases, at $16.06 \%$, followed by respiratory diseases, digestive diseases and genitourinary diseases. For those over 65 years, the highest CCE was for circulatory diseases, accounting for $34.55 \%$, followed by respiratory diseases and neoplasm, which accounted for a relatively high proportion (table 2 ).

\section{Medical institutions and the distribution of CCE for different age groups}

The CCE in 2016 was primarily incurred in hospitals, totalling ¥38.245 billion, or $76.42 \%$ of total CCE. Of this, general hospitals had the majority share, followed by traditional Chinese medicine and specialised hospitals. The treatment expenses incurred in primary healthcare institutions were $¥ 10.953$ billion, accounting for $21.89 \%$, with a relatively small proportion incurred in outpatient institutions and maternal and child healthcare institutions. Expenditures in relation to medical service providers differ across age groups.

The expenditure on treatment for those over 65 years was primarily for hospitals, accounting for $82.43 \%$, with a small proportion for primary medical institutions. Expenditure for those under 14 years was primarily for general hospitals, followed by primary medical institutions and specialised hospitals. Among different types of hospitals, the treatment expenditure for those under 14 years was higher in specialist hospitals, while that for the elderly was higher in traditional Chinese medicine hospitals (table 3).

\section{Financing distribution of CCE for different age groups}

In 2016, the total funding for the public financing scheme was $¥ 31.368$ billion for Xinjiang, accounting for $62.68 \%$ of CCE. Of this, government programmes accounted for $28.13 \%$, and social medical insurance programmes accounted for $34.55 \%$. Household health expenditures were $¥ 17.097$ billion, which accounted for $34.16 \%$, and voluntary funding schemes accounted for $3.16 \%$ of CCE. Funding schemes differ for different ages. The main source of funding for those under 14 years is family household health expenditure, which accounted for $47.82 \%$, followed by government funding and social health insurance. The source of funding for those over the age of 15 years is primarily social health insurance, 
Table 3 Curative care expenditure by health provider and age groups (\% )

\begin{tabular}{|c|c|c|c|c|}
\hline Medical service providers & $\leq 14$ years & $15-64$ years & $\geq 65$ years & Total \\
\hline Hospitals & 66.18 & 75.59 & 82.43 & 76.42 \\
\hline General hospital & 43.68 & 59.06 & 63.56 & 58.76 \\
\hline Specialised hospital & 17.32 & 5.02 & 3.95 & 5.88 \\
\hline Maternal and child care centres & 0.00 & 0.03 & 0.00 & 0.02 \\
\hline Primary medical institutions & 31.36 & 22.45 & 16.87 & 21.89 \\
\hline Total & 100.00 & 100.00 & 100.00 & 100.00 \\
\hline
\end{tabular}

followed by slightly different sources of funding. Government financing schemes are the primary source of funding for those in the 15-64 years age group, while it is family health expenditure for those over 65 years (table 4 ).

\section{DISCUSSION}

The burden of health expenditure of different age groups can be reflected in the treatment expenditure by age. It describes the matrix relationship between different age groups and diseases, institutional flows and financing schemes. It can further determine the economic burden of major diseases in different age groups, the medical treatment flow and the financing risk protection status.

To reduce $\mathrm{CCE}$, policy intervention should focus on key groups and diseases that consume expenditure. To control the growth in health expenditure, we should focus more on the group aged over 65 years, with higher policy preferences. ${ }^{1617}$ Considering that China has entered the ageing stage, we should strengthen preventive medicine and health services for the elderly to control their medical and health expenditure. ${ }^{18}$ For those over 65 years, it is important to reduce the expenditure burden of diseases through three-level prevention, standardised medication and reasonable treatment; strengthen the daily management of chronic diseases and cancer screening; and effectively control medical expenditures. ${ }^{19} 20$ Across age

\begin{tabular}{|c|c|c|c|c|}
\hline Health financing & $\begin{array}{l}\leq 14 \\
\text { years }\end{array}$ & $\begin{array}{l}15-65 \\
\text { years }\end{array}$ & $\begin{array}{l}\geq 65 \\
\text { years }\end{array}$ & Total \\
\hline $\begin{array}{l}\text { Public financing } \\
\text { scheme }\end{array}$ & 49.72 & 70.17 & 68.15 & 62.68 \\
\hline $\begin{array}{l}\text { Government } \\
\text { financing scheme }\end{array}$ & 34.40 & 27.65 & 22.34 & 28.13 \\
\hline $\begin{array}{l}\text { Social health } \\
\text { insurance }\end{array}$ & 15.32 & 42.52 & 45.81 & 34.55 \\
\hline $\begin{array}{l}\text { Voluntary financing } \\
\text { scheme }\end{array}$ & 2.47 & 3.47 & 3.53 & 3.16 \\
\hline $\begin{array}{l}\text { Family health } \\
\text { expenditure }\end{array}$ & 47.82 & 26.36 & 28.32 & 34.16 \\
\hline Total & 100.00 & 100.00 & 100.00 & 100.00 \\
\hline
\end{tabular}

groups, the highest expenditure for respiratory disease treatment was for those under 14 years. While protecting the health of children, it is also important to improve health expenditure as they grow. With the implementation of the two-child policy, we need to focus on children's health, or expenditure on disease treatment will continue to increase. ${ }^{21}$ It is also important for control expenditure to combine the children's treatment expenditure and diseases distribution. It is also necessary to raise the level of parental prevention of common diseases in children, especially those of the respiratory system. To increase disease prevention and control the expenditure of the young and middle-aged between 15 and 64 years, the screening of diseases should be improved and a healthy lifestyle advocated. ${ }^{22}$

The CCE flow differs across age groups, requiring appropriate allocation of medical resources. The CCE primarily flows to hospitals, indicating challenges in the flow of medical treatment and the allocation of medical funds among institutions at all levels. One of the main obstacles to achieving universal health coverage is the inefficient and inequitable use of health resources. ${ }^{23}$ Hospitals experience significant pressure on human resources and need to develop and improve medical mechanisms. ${ }^{24} 25$ Different levels of institutions undertake different treatment tasks according to the priority of the disease and the difficulty of treatment. It is important to adjust the scale of primary medical and health institutions, strengthen infrastructure construction and medical staff allocation, implement the contracted services of community general practitioners and share the treatment pressure. ${ }^{26}$ This study found that those under 14 years are the main target of primary medical institutions and specialised hospitals, while those over 65 years prefer visiting traditional Chinese medicine hospitals. Overall, the result indicates that the allocation of CCE in Xinjiang is unreasonable. To improve the medical level of primary medical institutions, it is necessary to focus on the diagnosis and treatment of frequently-occurring diseases and to treat the majority of diseases at such institutions. ${ }^{27} 28$ For the middle-aged and elderly, chronic disease intervention is the main way to reduce $\mathrm{CCE}$, and primary medical institutions are the main institutions for the prevention and treatment of chronic diseases. Such institutions not only disseminate 
knowledge about the risk factors of chronic diseases but also provide medicine and health counselling to help patients develop good living and working habits.

As the burden of CCE remains heavy, it is necessary to optimise financing schemes. There are significant differences in the health financing structure across all age groups. The coverage of the medical security system is one of the three dimensions of the concept of universal health coverage, that is, financial risk protection coverage ${ }^{29}$ China has achieved full coverage of the healthcare system around 2019, with more than $95 \%$ of residents enjoying basic healthcare. ${ }^{30}$ Health insurance population coverage is the basis, and the next challenge facing China is the scope of health insurance compensation, compensation level and so on. The results of this study show that the family burden of under-14-year-olds is heaviest. At present, some obstacles to the coverage and reimbursement of medical insurance for children, especially newborns, remain, which leads to a high proportion of children's medical expenses is being borne by the family. In the autonomous region, social medical insurance mainly manifests as 'hospitalisation insurance', with different types of medical insurance hospitalisation reimbursement rates. The proportion of use of hospitalisation service by the elderly is relatively higher than other age groups. Similarly, the proportion of social medical insurance reimbursement is correspondingly high, while the proportion of family burden is relatively low. A reasonable health financing system should focus on public financing schemes such as government and social medical insurance, and reduce the personal cash health expenditure by the family. ${ }^{31}$ If the health financing system is overly dependent on household out-of-pocket payment, it will easily lead to catastrophic expenditures or poverty due to illness. ${ }^{32} 33$ Owing to physical reasons, children's resistance to disease is poor and they are more likely to get sick, which not only leads to a loss of health but also incurs significant expenditure for treatment. Furthermore, children rely on the support and care of family and society, therefore, the expenditure for disease treatment will be directly converted into an economic burden on the family and society. ${ }^{21}$ Encouraging the development of children's commercial medical insurance can also enhance health security. The coverage of basic medical insurance after integrating the medical insurance of urban and rural residents will be conducive to the stable development and balance of the financing system led by public financing. ${ }^{34}{ }^{35}$ Enterprises and individuals should be encouraged to participate in commercial medical insurance, and the stability of the financing structure should be strengthened to a certain extent.

In general, different age groups have different treatment expenditures, disease conditions and medical institutional tendencies. Therefore, it is necessary to formulate corresponding health policies for different age groups to control the growth of treatment expenditure. Regular physical examination of middle-aged and elderly people should be strengthened and early detection and early treatment should be implemented, so as to prevent minor diseases from developing into major diseases and consuming more health resources. We should strengthen the development of community-level medical and health institutions, improve the medical skills of such personnel and make these the main institutions for treating basic diseases. To encourage the development of special commercial insurance for chronic diseases and health risks, the diversity of financing should be increased.

This study has the following limitations. The methodology is based on the SHA 2011 accounting framework, developed by the China National Health Development Research Center. As this is based on the health of people in China, the results may not apply to all countries. As only the overall beneficiaries of CCE in Xinjiang are analysed, the region was not subdivided into different cities; therefore, we cannot present efficient policy suggestions for different cities. Finally, this study only analysed the data for 1 year and it was not possible to judge the change in CCE in Xinjiang.

\section{CONCLUSION}

This study used SHA 2011 to capture large data and analysed it from the newly added beneficiary dimension. The results of this study could help to understand the curative expenditure distribution and adjust financial expenditures for rationally allocating curative and prevention expenditures, and promote efficient use in health resources. This study found that the use of health resources in primary medical institutions were insufficient, resulting in high out-of-pocket expenses and heavy medical burden. Primary medical institutions need to improve health services ability, along with the need to optimise the CCE financing scheme. Therefore, the health policymaking department should optimise relevant policies to lessen the medical burden of diseases.

Acknowledgements The authors express thanks to China National Health Development Research Center for their help with SHA 2011 analysis, and we also gratefully acknowledge the support of the Health Commission of Xinjiang Uyghur Autonomous Region. Thanks to Xinjiang's Department of Finance, Civil Affairs and other departments for providing basic accounting data, and thanks for the data support provided by the sampled medical and health institutions. We would like to thank Editage (www.editage.cn) for English language editing. Also, we would like to thank the associate editor and reviewers for their careful review and meaningful comments, which helped us improve this manuscript.

Contributors HF had full access to the study and takes responsibility for the integrity of the data and the accuracy of the data analysis. Concept and design: DR and LM. Acquisition, analysis and interpretation of data: All authors. Drafting of the manuscript: HF and KP. Helping revise the manuscript: XL, LM and DR. Statistical analysis: LZ, HF and KP.

Funding This work was supported by the Ministry of Education in China Project of Humanities and Social Sciences, Xinjiang (Project No.18XJJCZH001).

Competing interests None declared.

Patient consent for publication Not required.

Ethics approval Ethical approval was obtained from the Institutional Ethics committee of the First Affiliated Hospital of Shihezi University School of Medicine (Approval number: 2018-121-01).

Provenance and peer review Not commissioned; externally peer-reviewed. 
Data availability statement The data that support the findings of this study are available from third party. Restrictions apply to the availability of these data, which were used under license for this study.

Open access This is an open access article distributed in accordance with the Creative Commons Attribution Non Commercial (CC BY-NC 4.0) license, which permits others to distribute, remix, adapt, build upon this work non-commercially, and license their derivative works on different terms, provided the original work is properly cited, appropriate credit is given, any changes made indicated, and the use is non-commercial. See: http://creativecommons.org/licenses/by-nc/4.0/.

\section{ORCID iDs}

Honghong Feng http://orcid.org/0000-0003-0385-6704

Dongsheng Rui http://orcid.org/0000-0001-8701-6600

\section{REFERENCES}

1 Boerma T, Eozenou P, Evans D, et al. Monitoring progress towards universal health coverage at country and global levels. PLoS Med 2014;11:e1001731.

2 Organization WH. World health report 2010: health systems financing - the path to universal coverage. Geneva Switzerland Who, 2010.

3 Zhai T, Wan Q, Chai P, et al. A decomposition analysis of recent health expenditure growth in China: is population ageing a significant effecting factor? China Popul Dev Stud 2020;4:45-57.

4 Guo F, Wan Q, Zhang Y. The estimating results on China preventive care expenditure based on sha 2011. Chin Health Econ 2015:34:20-2.

5 Chai P, Zhang Y, Wan Q. Estimation results of China curative care expenditure based on sha 2011. Chin Health Econ 2015;03:19-21.

6 Chai P, Zhang Y, Zhou M, et al. Technical and scale efficiency of provincial health systems in China: a bootstrapping data envelopment analysis. BMJ Open 2019;9:e027539.

7 Cao GW, Zhang BX, Chen XP. [Consideration on improving public health emergency management ability of current medical health system]. Zhonghua Liu Xing Bing Xue Za Zhi 2020;41:E072.

8 Zhang Y, Fu W, Wang X. Challenges and countermeasures of people-centred integrated care model in China. Chin Health Res 2017;20:525-30.

9 Bartsch SM, Ferguson MC, McKinnell JA, et al. The potential health care costs and resource use associated with COVID-19 in the United States. Health Aff 2020;39:927-35.

10 The Lancet Oncology. COVID-19 and the US health insurance conundrum. Lancet Oncol 2020;21:733.

11 Wang $F$. The roles of preventive and curative health care in economic development. PLoS One 2018;13:e0206808.

12 OECD, Organization WH, Eurostat. A system of health accounts, 2011.

13 Mueller M, Morgan D. New insights into health financing: first results of the International data collection under the system of health accounts 2011 framework. Health Policy 2017;121:764-9.

14 Zhai T, Zhang Y, Wan Q. New system of health accounts introduction of system of health accounts 2011. Chin Health Econ 2013;01:15-17.

15 Zhai T, Zhang Y, Wan Q. Methodological research on China health expenditure estimation based on sha 2011. Chin Health Econ 2015;03:11-13.

16 Duan W, Zheng A, Mu X, et al. How great is the medical burden of disease on the aged? Research based on "System of Health Account 2011". Health Qual Life Outcomes 2017;15:134.
17 Jiang Y, Zhao X, Zhao L. Analysis on the distribution of curative care expenditure for the beneficiaries of treatment services in Beijing : based on the system of health account 2011. Chin J Health Policy 2018;07:7-12.

18 Yang Y, Zheng A, Li M, et al. Medical economic burden of the ageing population: a multistage sampling analysis of 3532517 cases. Lancet 2016;388:S79.

19 Huang S, Jia J, Xiong K. Analyzing the treatment cost accounting of the elderly in Sichuan province based on the "system of health accounts (SHA) 2011". Chin Health Serv Manag 2019.

20 Luo J, Li Y, Li J. Analysis of the Status-quo of service in primary health care institutions in Tianjin-Based on the perspective of regular health costs. Health Econ Res 2019;08:50-3.

21 Li M, Zheng A, Duan W, et al. How to apply sha 2011 at a subnational level in China's practical situation: take children health expenditure as an example. J Glob Health 2018;8:010801.

22 Yang L, Huang Y, Sun Q. Analyzing the beneficiary groups of curative care expenditure in Sichuan based on sha 2011. Chin Health Ser Manag 2017;11:41-4.

23 Dye C. Research for universal health coverage. World health report, 2013.

24 Zang S, Zhan H, Zhou L, et al. Research on Current Curative Expenditure among Lung Cancer Patients Based on the "System of Health Accounts 2011": Insights into Influencing Factors. J Cancer 2019;10:6491-501.

25 Song S, Ma X, Zhang L, et al. Precision targeting for more equitable distribution of health professionals in rural China. Health Policy Plan 2018;33:821-7.

26 Dong Y, Liu C, Zhou P, et al. How serious is the economic burden of diabetes mellitus in Hainan province? a study based on "system of health account 2011". Diabetes Ther 2019;10:2251-63.

$27 \mathrm{He} \mathrm{J}$, Yin Z, Duan W, et al. Factors of hospitalization expenditure of the genitourinary system diseases in the aged based on "System of Health Account 2011" and neural network model. J Glob Health 2018;8:020504

28 Ren Y, Yang X, Shen C. Study on the distribution of treatment costs for different age groups in Shaanxi Province-Based on regular health costs. Health Econ Res 2019.

29 Ahmed S, Hasan MZ, MacLennan M, et al. Measuring the efficiency of health systems in Asia: a data envelopment analysis. BMJ Open 2019;9:e022155.

30 Haoran P. Integration of china's basic medical insurance system:theoretical debate, practical progress and future prospects. Academic Monthly 2020;52:55-65.

31 Zhan $\mathrm{H}$, Wu Q, Zang S, et al. How were situations of preventive and curative care expenditure for AIDS and medical burden of patients? Research based on "System of Health Accounts 2011". BMC Public Health 2020;20:169.

32 Nakovics MI, Brenner S, Robyn PJ, et al. Determinants of individual healthcare expenditure: a cross-sectional analysis in rural Burkina Faso. Int J Health Plann Manage 2019;34:e1478-94.

33 Zheng A, Duan W, Zhang L, et al. How great is current curative expenditure and catastrophic health expenditure among patients with cancer in China? A research based on "System of Health Account 2011". Cancer Med 2018;7:4036-43.

34 Song S, Yuan B, Zhang L. Increased inequalities in health resource and access to health care in rural China. 16, 2018.

35 Chen Y, Yin Z, Xie Q. Suggestions to ameliorate the inequity in urban/ rural allocation of healthcare resources in China. Int $J$ Equity Health 2014;13:34 